\title{
Country-of-Origin Labelling, Food Traceability Drivers and Food Fraud: Lessons from Consumers' Preferences and Perceptions
}

Michail Bitzios, Lisa Jack, Sally-Ann Krzyzaniak and Mark Xu*

Many factors influence consumers' perceptions and purchasing decisions, with product labelling forming the primary means of communication. The extent to which labels should contain information about traceability is debated. Whilst traceability is an important tool used by food business organisation and regulators in assuring food safety, other drivers for information about traceability are less well understood. This paper reviews the issues related to drivers for traceability from a consumer perspective, and evaluates country-of-origin labelling ( $\mathrm{COOL}$ ), enabling technologies and food fraud as potentially significant drivers in consumer requirements for information. The implications for risk assessment, systems implementation and communications about traceability are also considered.

\section{Introduction}

Consumer behaviour in making purchasing decisions is based on a number of different factors, such as personal preferences, attitudes towards certain food product characteristics (sensory and nonsensory), price, ethical concerns, health claims and others ${ }^{1}$. A variety of social, cultural and economic aspects may also influence one's purchasing behaviour ${ }^{2}$. Although new technologies increase the methods by which information may be provided to consumers, food labels remain the key means of providing information at the point of purchase, and hence they continue to play an important role in influencing consumer purchasing decisions.

Labels enable consumers to identify products and so can facilitate repeated purchases when satisfaction has occurred. In such cases, labels become the trusted extrinsic cues that may be used as a search attribute during purchasing ${ }^{3}$. This, in turn, means that labels may positively impact on

\footnotetext{
* Michail Bitzios, Research Fellow; Lisa Jack, Professor in Accounting; Sally-Ann Krzyzaniak, Research Fellow and Mark Xu, Professor of Information Management, Portsmouth Business School, University of Portsmouth. Sally-Ann Krzyzaniak is the corresponding author, email: Sally-Ann.Krzyzaniak@port.ac.uk ${ }^{1} \mathrm{~J}$. Prescott and others, 'Motives for food choice: a comparison of consumers from Japan, Taiwan, Malaysia and New Zealand' (2002) 13 Food Quality and Preference 489

${ }^{2}$ A Eertmans, $\mathrm{F}$ Baeyens and $\mathrm{O}$ Van Den Bergh, 'Food likes and their relative importance in human eating behavior: review and preliminary suggestions for health promotion' [2001] Health Education Research 443 ${ }^{3}$ Alberto Bernués, Ana Olaizola and Kate Corcoran, 'Extrinsic attributes of red meat as indicators of quality in Europe: an application for market segmentation' (2003) Food Quality and Preference 265
} 
consumer welfare by providing better consumer protection and allowing people to make better choices ${ }^{4}$. However, food labels carry a wide array of information which can be difficult for the consumer to understand and absorb. This may negatively impact consumers' confidence in products' attributes.

Consumers are concerned about the trustworthiness of the information they receive, from food labels and other sources ${ }^{6}$. Publicised cases include misleading health benefits, mislabelled products ${ }^{7}$, false product origins and counterfeit labels. Nevertheless, consumers are aware of the nuances of labelling, such as the difference between 'orange juice' and 'orange flavoured drink'. For fresh foods, consumers have expressed concerns about the origins of food products and the authenticity of ingredients. There are three aspects to these concerns. The first relates to food safety and knowing where the food has been handled and by whom. The second relates to the perceived quality of food being purchased and the last relates to the risk of being sold something under false pretences, which may have food safety or quality implications.

These concerns have largely been conflated into one topic - traceability. Of course traceability, per se, is not an indication of product quality. Extensive research has been conducted on traceability technologies and systems, consumer preference and consumers' willingness to pay for food safety and food quality information. A number of drivers of traceability have been identified, such as food safety, value based labelling, country-of-origin and technology. However there is, as yet, little or no literature on consumer perceptions, preferences or willingness to pay for information relating to traceability and the prevention of food fraud.

Despite the fact that food fraud is not a new phenomenon ${ }^{8}$, food authenticity and the accuracy and legitimacy of labels are hot topics among those involved in the food industry, as well as researchers, governments and consumers, driven in part by the 2013 horse meat scandal in the EU ${ }^{9}$. Many food

\footnotetext{
${ }^{4}$ B Krissoff and others, 'Country-of-Origin Labeling: Theory and Observation' (USDA 2004)

${ }^{5}$ Ronald W. Ward, Julian Britz and Isabel de Felipe, 'Competing Supplies of Olive Oil in the German Market: An Application of Multinomial Logit Models' [2003] Agribusiness 393

${ }^{6}$ Michiel Korthals, 'Ethical Rooms for Maneuver and Their Prospects Vis-à-vis the Current Ethical Food Policies in Europe' [2008] Journal of Agricultual and Environmental Ethics 249

${ }^{7}$ Non-compliance with allergen labelling, which is a key food safety issue for vulnerable consumers, accounted for $14 \%$ of recorded food incidents in the UK in 2015 (Food Standards Agency and Food Standards Scotland 'The Annual Report of Food Incidents' < https://www.food.gov.uk/news-updates/news/2016/15190/fsaannual-report-of-incidents-2015-published $>$ accessed $4^{\text {th }}$ November 2016)

8 Peter Shears, 'Food fraud - a current issue but an old problem' [2010] British Food Journal 198

${ }^{9}$ Francesco Montanari, Cesare Varallo and Daniele Pisanello, Volume 7 Issue 1 'Food Fraud in the EU' [2016]

European Journal of Risk Regulation 197
} 
products can be subject to adulteration, but there are some categories of products that are more prone to fraud. In the USA, as Shug reports using data from the Food Protection and Defence Institute $(\text { FPDI })^{10}$, most food fraud incidents have been reported in fish/seafood products followed by dairy and meat products.

Food fraud is considered a much broader term than economically motivated adulteration, as according to Spink and Moyer ${ }^{11}$ it covers the "deliberate and intentional substitution, addition, tampering, or misrepresentation of food, food ingredients, or food packaging; or false or misleading statements made about a product, for economic gain". In fact, FPDI's data shows that dilution, substitution, artificial enhancement, mislabelling and counterfeiting are the top methods for adulterating food products. Another relevant factor for consideration is the increasing complexity and globalisation of food supply chains (which of course directly impacts the complexity of food traceability) which were highlighted as a point of vulnerability for fraud in the Elliott report written for the UK government following the 2013 horsemeat scandal ${ }^{12}$.

Several guidance documents have been written with the aim of reducing the risk of the deliberate contamination of the food supply chain and / or to help the food industry reduce its vulnerability to food fraud ${ }^{13} 14$ since 2013. The mapping of food supply chains - i.e. gathering and maintaining enhanced traceability information - is embedded within these approaches. Assurance standards, such as the BRC Global Standard for Food Safety Issue 7 also promote enhanced transparency and traceability in food supply chains ${ }^{15}$. However, there is a lack of empirical academic work to demonstrate the extent or efficacy of these developments and to explore consumers' perception of the relationship between traceability and the prevention of food fraud.

Our question therefore is: will food fraud develop from being a driver of traceability by FBOs, affecting primarily risk assessment processes, to one that consumers recognise, if so, how this might impact

\footnotetext{
${ }^{10}$ Debra Schug, 'Preventing food fraud' Food Engineering (Troy Michigan January 2016) 109

${ }^{11}$ John Spink and Douglas C Moyer, 'Defining the Public Health Threat of Food Fraud' [2011] Journal of Food Science R157

12 Department for Environment, Food and Rural Affairs and Food Standards Agency, ' Elliott Review into the Integrity and Assurance of Food Supply Networks Final Report' (National Food Crime Prevention Framework July 2014)' < https://www.gov.uk/government/publications/elliott-review-into-the-integrity-and-assurance-offood-supply-networks-final-report > accessed 4th November 2016 (Elliott Report)

${ }^{13}$ British Standards Institute, 'PAS 96: 2014, Guide to Protecting and Defending Food and Drink from Deliberate Attack' (3 ${ }^{\text {rd }}$ Edition, BSI Standards Ltd 2014) < https://www.food.gov.uk/sites/default/files/pas962014-food-drink-protection-guide.pdf >accessed 29th November 2016

${ }^{14}$ SSAFE, 'Food Fraud Vulnerability Assessment Tool' (2016) < http://www.ssafe-food.org/our-projects/ > accessed $29^{\text {th }}$ November 2016

${ }^{15}$ British Retail Consortium, 'Global Standard Food Safety Issue 7' (British Retail Consortium 2015)
} 
systems implementation and labelling practices? A secondary question is to what extent knowledge of consumer preference might be a driver for traceability through food labelling.

In order to provide an initial answer to these questions, we carry out a review of the relevant literature, which identifies consumer perceptions, preferences and willingness to pay for traceability information, and evaluates the extent to which these factors can be seen as a driver of traceability and deterrence of food fraud via food labelling.

\section{Drivers of traceability}

A number of drivers for food traceability have been identified ${ }^{16}$, in terms of both the implementation of traceability systems and the communication of traceability information. A considerable amount of research has examined consumer perceptions of traceability information carriers ${ }^{18}$, consumer

\footnotetext{
${ }^{16}$ Kine Mari Karlsen and others, 'Literature review: Does a common theoretical framework to implement food traceability exist?' (2013) 32 Food Control 409

${ }^{17} \mathrm{P}$ Olsen, 'Food traceability process mapping. Standard method for analyzing material flow, information flow and information loss in supply chains' (Harmonizing methods for food traceability process mapping and cost/benefit calculations related to the implementation of electronic traceability systems Workshop hosted by Nofima in association with TRACE project, Tromso Norway, February 2009)

18 Polymeros Chrysochou, George Chryssochoidis and Olga Kehagia, 'Traceability information carriers. The technology backgrounds and consumers' perceptions of the technological solutions' (2009) 53 Appetite 322
} 
preferences and willingness-to-pay for food safety and traceability attributes ${ }^{19} 20212223242526$ and consumer attitudes and behavioural intentions for food that can be traced back to its origin ${ }^{2728} 29$. Other qualitative research has examined consumers' understanding of and expectations from traceability for different products ${ }^{30}$. Similar research has looked at the determining factors for consumers' use of labels, as well as their preferences regarding the type and means of information about traceability ${ }^{31}$.

It should be noted that studies on consumers perceptions of traceability conducted thus far have primarily focused on issues specifically related to food risk and safety ${ }^{32}$ and have therefore focussed on traceability for meat, as this is considered a potentially risky food product by consumers 3334 .

\footnotetext{
${ }^{19}$ Frode Alfnes and Kyrre Rickertsen, 'European Consumers' Willingness to Pay for U.S. Beef in Experimental Auction Markets' [2003] American Journal of Agricultural Economics 396

20 Junfei Bai, Caiping Zhang and Jing Jiang, 'The role of certificate issuer on consumers' willingness-to-pay for milk traceability in China' [2013] Agricultural Economics 537

${ }^{21}$ D L Dickinson and D Bailey, 'Meat traceability: Are US consumers willing to pay for it?' [2002] Journal of Agricultural and Resource Economics 348

22 D L. Dickinson and Dee Von Bailey, 'Experimental Evidence on Willingness to Pay for Red Meat Traceability in the United States, Canada, the United Kingdom, and Japan' [2005] Journal of Agricultural and Applied Economics 537

${ }^{23}$ Maria L. Loureiro and Wendy J. Umberger, 'A choice experiment model for beef: What US consumer responses tell us about relative preferences for food safety, country-of-origin labeling and traceability' (2007) 32 Food Policy 496

${ }^{24}$ Jutta Roosen, Jayson L. Lusk and John A. Fox, 'Consumer Demand for and Attitudes Toward Alternative Beef Labelling Strategies in France, Germany, and the UK' [2003] Agribusiness 77

${ }^{25}$ Bodo Steiner, Fei Gao and Jim Unterschultz, 'Alberta consumers' valuation of extrinsic and intrinsic red meat attributes: A choice experimental approach' [2010] Canadian Journal of Agricultural Economics/Revue canadienne d'agroeconomie 171

${ }^{26}$ David Ubilava and Kenneth Foster, 'Quality certification vs. product traceability: Consumer preferences for informational attributes of pork in Georgia' (2009) 34 Food Policy 305

${ }^{27}$ Mei-Fang Chen, 'Consumer attitudes and purchase intentions in relation to organic foods in Taiwan: Moderating effects of food-related personality traits' (2007) 18 Food Quality and Preference 1008 ${ }^{28}$ Brian E Mennecke and others, 'A study of the factors that influence consumer attitudes toward beef products using the conjoint market analysis tool' [2007] Journal of Animal Science 2639

${ }^{29}$ Wim Verbeke and others, 'European beef consumers' interest in a beef eating-quality guarantee: Insights from a qualitative study in four EU countries' (2010) 54 Appetite 289

${ }^{30}$ Olga Kehagia and others, 'European Consumers' Perceptions, Definitions and Expectations of Traceability and the Importance of Labels, and the Differences in These Perceptions by Product Type' [2007] Sociologia Ruralis 400

${ }^{31}$ Wendy Van Rijswijk and Lynn J. Frewer, 'Consumer needs and requirements for food and ingredient traceability information' [2012] International Journal of Consumer Studies 282

${ }^{32}$ G. Giraud and C. Amblard, 'What does traceability mean for beef meat consumer?' (2003) 23 Food Science 40

33 supra, note 21

${ }^{34} \mathrm{X}$ Gellynck and W Verbeke, 'Consumer perception of traceability in the meat chain' [2001] Agrarwirtschaft, 368

35 Jill E Hobbs and others, 'Traceability in the Canadian red meat sector: do consumers care?' [2005] Canadian Journal of Agricultural Economics/Revue canadienne d'agroeconomie 47
} 


\section{Driver 1: Food Safety}

Food traceability/product tracing is defined by the Codex Alimentarius Commission (CAC) ${ }^{36}$ as:

"the ability to follow the movement of a food through specified stage(s) of production, processing and distribution".

As such it is clear that the responsibility for food traceability lies with actors along the entire length of the supply chain, but this does not mean that complete traceability information passes along the entire length of the supply chain with every product transaction or ingredient transformation. Even in the European Union (EU), where food business organisations (FBOs) face some of the most stringent requirements for traceability in the world ${ }^{37}$, regulation for general food products only requires FBOs to identify their immediate suppliers and customers ${ }^{38}$, i.e., they must be able to trace finished goods and ingredients "one step back" and "one step forwards" along their supply chain ${ }^{39}$. The emphasis under the law is in ensuring that in the event of a food safety issue, which necessitates the withdrawal of product from sale or the recall of products from consumers, the required traceability information can be provided to enforcement authorities within a short timescale to enable the product withdrawal/recall.

Whilst the legislation does not require that retailers trace finished products to every individual purchaser, FBOs are required to label products with certain information to enable products to be recalled from customers in the event of a food safety or quality issue. Under EU legislation, the mandatory labelling elements concerned in this for all product categories are the:

- Product legal name

- Name and address of the responsible FBO. This does not show origin of the product

- LOT code and date of minimum durability (best before or use by date, as applicable)

\footnotetext{
${ }^{36}$ Codex Alimentarius Commission of the FAO and WHO, 14th Proceedural Manual (2004)

37 Sylvain Charlebois and others, 'Comparison of Global Food Traceability Regulations and Requirements' [2014] Comprehensive Reviews in Food Science and Food Safety 1104

${ }^{38}$ Regulation (EC) No 178/2002 Of The European Parliament And Of The Council of 28 January 2002 laying down the general principles and requirements of food law, establishing the European Food Safety Authority and laying down procedures in matters of food safety, in OJ 2002 L31/1, art 18

${ }^{39}$ Additional requirements for labelling and traceability are laid down in EU legislation for specific food categories as discussed in the following sections of the paper.
} 
- Hygiene marks (for certain fresh foods) and approved premises code. This does not show origin of the product.

Figure 1 displays a typical example of a food product label. The mandatory elements of the label related to traceability are clearly marked. The branding and "fancy name" of a product are not mandatory elements of labelling, but they are certainly important in helping consumers to identify products affected by any product recall.

\section{Figure 1. Elements on a food label related to traceability}

[Insert Figure 1 here]

Consumers also understand food safety to be a key driver for food traceability, as they correctly identify that the traceability is intended to help producers, manufacturers and suppliers in the supply chain so that risky foods can be withdrawn from the market more easily ${ }^{40}$. However, this research also found that consumers associate traceability with higher product prices, which might be perceived as a negative driver for FBOs to implement and communicate product traceability.

\section{Driver 2: Consumer choice and value based labelling schemes}

European legislation also sets out additional requirements, in terms of labelling and traceability, for categories of food where it is felt to be required by consumers in order for them to make a fully informed choice about the products they purchase. This includes the positive labelling of foods produced using genetically modified ingredients or foods treated with ionising radiation and the labelling of organic products. In all cases, additional traceability information is required to support the presence (or absence) of such labelling.

Whilst the EU regulatory environment sets an expectation for enhanced traceability for the products discussed above, food producers, manufacturers and retailers have established a number of valuebased labelling (VBL) schemes designed to communicate additional product characteristics, including product quality, authenticity and traceability, to the consumer. In the UK, these range from producer-

\footnotetext{
${ }^{40}$ Wendy van Rijswijk and others, 'Consumer perceptions of traceability: A cross-national comparison of the associated benefits' (2008) 19 Food Quality and Preference 452
} 
led schemes, such as Specially Selected Scotch Beef and the Little Red Tractor logo, to independent schemes such as Freedom Food and retailer schemes (e.g. Tesco's "Finest", Sainsbury's "Taste the Difference" $)^{41}$.

From a consumer perspective, attributes portrayed by value based labelling would be considered as discriminating factors differentiating product offerings in a competitive marketplace ${ }^{42}$. Hence it could be expected that such labelling would be a core driver for more comprehensive product traceability. Although an increasing number of producers have subscribed to VBL schemes, their perceptions tend to be that the process of becoming a VBL scheme member adds substantial costs without market benefits (e.g. market premium) ${ }^{43}$. Producers believe that whilst retailers have driven demand for VBL schemes $^{44}$, consumers have little or no understanding of what the labels mean or how they might benefit them ${ }^{45}$. Other research has found that despite their potential to influence quality expectations and relieve risk, quality labels are often ignored or misinterpreted by consumers, hence yielding quality inferences that go beyond what the labels really stand for ${ }^{46} 47$.

There is also evidence to suggest that traceability might have more value and will be of interest to consumers when it is accompanied by other information such as quality labels ${ }^{48}{ }^{49}$, which supports a VBL approach rather than communication only on product traceability.

In conclusion, whilst the primary function of value-based labels is to signify superior safety and quality (in particular at the point of purchase), it appears that their potential to drive consumer demand and increase the drive for traceability might not be fully realised. Looking at meat as a specific example, there are a number of quality attributes, such as humane animal treatment and origin, that can be signified by certain aspects of mandatory labelling or by VBL schemes, but which consumers are unable

\footnotetext{
${ }^{41}$ Morven McEachern, G and Monika Schröder, J A, 'Integrating the voice of the consumer within the value chain: a focus on value-based labelling communications in the fresh-meat sector' [2004] Journal of Consumer Marketing 497

42 Susan Baker, New consumer marketing: managing a living demand system (John Wiley \& Sons Ltd 2003)

${ }^{43}$ Carol Morris and Craig Young, 'Seed to shelf', 'teat to table', 'barley to beer' and 'womb to tomb': discourses of food quality and quality assurance schemes in the UK' (2000) 16 Journal of Rural Studies 103 ${ }^{44}$ R. Early, 'Farm assurance: benefit or burden' (1998) 159 Journal of Royal Agricultural Society of England 33

${ }^{45}$ Keith Walley, Stephen Parsons and Maggie Bland, 'Quality assurance and the consumer' [1999] British Food Journal 148

${ }^{46}$ Klaus G Grunert, 'Food quality and safety: consumer perception and demand' [2005], European Review of Agricultural Economics 369

${ }^{47}$ Wim Verbeke and Jacques Viaene, 'Beliefs, attitude and behaviour towards fresh meat consumption in Belgium: empirical evidence from a consumer survey' (1999) 10 Food Quality and Preference 437 48 supra, note 35

${ }^{49}$ Wim Verbeke and Ronald W. Ward, 'Consumer interest in information cues denoting quality, traceability and origin: An application of ordered probit models to beef labels' (2006), 17 Food Quality and Preference 453
} 
to verify as they use or consume the meat. It appears that consumer trust and loyalty can only be enhanced further if they are offered access to information detailing the underpinning standards of the labelling, including traceability information.

\section{Driver 3: Country-of-Origin Labelling}

Country-of-origin labelling (COOL) can be split into three different categories under EU legislation.

For the majority of products, labelling of country or place of origin, or of the provenance of a food, is only required when a failure to provide it might:

"mislead the consumer as to the true country of origin of the product ....., in particular if the information accompanying the food or the label as a whole would otherwise imply that the food has a different country of origin or place of provenance". ${ }^{50}$

There are additional mandatory COOL requirements for a number of "fresh" foods, namely fruits and vegetables, honey, olive oil, fish and unprocessed meats. Comprehensive $\mathrm{COOL}$ / traceability labelling for beef was introduced following the BSE crisis, i.e., it was introduced as part of the measures implemented to ensure the safety of the beef supply chain. This has since been extended to cover the meat of swine, sheep, goats and poultry ${ }^{51}$ and now these meats must be labelled with country of birth (for beef only) rearing and slaughter ${ }^{52}$ (along with other traceability information such as codes for processing plants) with $\mathrm{FBOs}$ being required to record and communicate appropriate traceability information along the food chain to enable the appropriate labelling to be made.

Figure 2 illustrates a beef label, typically found in UK grocery stores, which explains the elements related to COOL.

\footnotetext{
${ }^{50}$ European Parliament and Council Regulation, Regulation (EU) No 1169/2011 of the European Parliament and of the Council of 25 October 2011 on the provision of food information to consumers, amending Regulations (EC) No 1924/2006 and (EC) No 1925/2006 of the European Parliament and of the Council, and repealing Commission Directive 87/250/EEC, Council Directive 90/496/EEC, Commission Directive 1999/10/EC, Directive 2000/13/EC of the European Parliament and of the Council, Commission Directives 2002/67/EC and 2008/5/EC and Commission Regulation (EC) No 608/2004 Text with EEA relevance [2011], OJ L304/54, art. 26, par. 2 point a); the "FIC Regulation"

${ }^{51}$ Commission Regulation, COMMISSION IMPLEMENTING REGULATION (EU) No 1337/2013 of 13 December 2013 laying down rules for the application of Regulation (EU) No 1169/2011 of the European Parliament and of the Council as regards the indication of the country of origin or place of provenance for fresh, chilled and frozen meat of swine, sheep, goats and poultry [2013] OJ L335/56

${ }^{52}$ For a discussion of the new legislation, and the definitions of "country of rearing" pertaining to the different animals, see Ignacio Carreño, 'New EU Rules on the Country of Origin Labelling for meat of Swine, Sheep, Goats and Poultry' Volume 5 Issue 2 [2014] European Journal of Risk Regulation 213
} 


\section{Figure 2. Understanding of country-of-origin information on a typical beef label ${ }^{53}$}

[Insert Figure 2 here]

There are also on-going debates about whether $\mathrm{COOL}$ should be extended to other food categories such as milk, unprocessed foods, single ingredient foods and ingredients which make up more that $50 \%$ of any food ${ }^{54}$.

Whilst the law on meat labelling has been extended, there is data to suggest that consumers do not understand or utilise this labelling to influence purchase decisions. Verbeke and colleagues ${ }^{55}$ reported that consumers classified some of the compulsory EU beef label indications (e.g., traceability and processing reference codes) as the least important cues compared to other cues on beef labels like expiration date, meat type and quality marks. As required by the FIC Regulation ${ }^{56}$, the European Commission has issued several reports on the potential for extending COOL, e.g. to meat as an ingredient ${ }^{57}$ and for unprocessed foods, single ingredient products and ingredients that represent more than $50 \%$ of a food ${ }^{58}$. These reports echo earlier work, showing that whilst COOL does impact consumers purchasing behaviour it is less important than aspects such as taste, appearance and expiration dates.

The final category of products covered by $\mathrm{COOL}$ are those marketed under the EU "protected names scheme", the definitions of which are shown in Table 1.

Table 1. EU protected names scheme $\mathrm{e}^{59}$

[Insert table 1 here]

\footnotetext{
${ }^{53}$ Food Standards Agency Scotland, Consumer guide to country of origin information on food labels (2008) ${ }^{54}$ supra, note 50

${ }^{55} \mathrm{~W}$. Verbeke, R. W. Ward and T. Avermaete, 'Evaluation of publicity measures relating to the EU beef labelling system in Belgium' (2002) 27 Food Policy 339

${ }^{56}$ Supra, note 47

${ }^{57}$ European Commission, REPORT FROM THE COMMISSION TO THE EUROPEAN PARLIAMENT AND THE COUNCIL regarding the mandatory indication of the country of origin or place of provenance for meat used as an ingredient, 755 (2013)

${ }^{58}$ European Commission, REPORT FROM THE COMMISSION TO THE EUROPEAN PARLIAMENT AND THE COUNCIL regarding the mandatory indication of the country of origin or place of provenance for unprocessed foods, single ingredient products and ingredients that represent more than 50\% of a food, 204 (2015) ${ }^{59}$ European Parliament and Council Regulation, Regulation (EU) No 1151/2012 of the European Parliament and of the Council of 21 November 2012 on quality schemes for agricultural products and foodstuffs [2012] OJ L $343 / 55$ art 3
} 
The use of these schemes encourages diverse agricultural production, protects product names from misuse and imitation and helps consumers by giving them information concerning the specific character of the products. All require the FBOs involved in their production to collect and hold comprehensive traceability information to support marketing products with these attributes.

Some research indicates that consumers relate traceability to the origin of products ${ }^{60}$. This is supported by research on purchasing behaviour of Greek wine consumers ${ }^{61}$, which showed that the probability of choosing traceability as an important quality cue increases when people have an urban origin. Further, traceability was regarded as a quality characteristic when consumers received more information from the product label rather than from media sources. This may suggest that consumers of urban origin seek socially desirable constructs, such as authenticity and tradition, based on the product label. Consequently, traceability certification and geographic association serve as quality schemes that reduce the risk associated with the consumption of new products. Hence communication of the product's origin, whether it be under the EU protected names scheme or any other form of $\mathrm{COOL}$, might be seen as a form of VBL, and may be of particular value for new product introductions.

\section{Driver 4: Traceability carriers - enabling technologies}

At its simplest, the legal requirements for product traceability can be accomplished using a handwritten paper-and-pen system. However, an array of different technologies, classified as "traceability carriers", is now available to trace and track food products from "field to fork". In the main, such technologies are utilised by food supply chain actors to discharge their legal obligations to trace and track products. They may also give economic benefits to FBOs by aiding production planning and strengthening relationships with suppliers and customers.

From a consumer perspective, a perceived benefit of traceability carriers is their ability to provide additional product-related information. It has also been argued $^{62}$ that consumers' perception of a traceability carrier depends on its ability to enhance consumer confidence (interpreted by consumers in terms of reliability and credibility of product information) in the product information offered.

\footnotetext{
${ }^{60} \mathrm{G}$ Giraud and R Halawany, 'Consumers perception of food traceability in Europe.' (98th EAAE Seminar 'Marketing Dynamics within the Global Trading System: New Perspectives', Chania, Crete July 2006)

${ }^{61}$ Efthalia Dimara and Dimitris Skuras, 'Consumer evaluations of product certification, geographic association and traceability in Greece' [2003], European Journal of Marketing 690

${ }^{62}$ supra, note 18
} 
Another factor that influences consumers' perception of a traceability carrier is the level of convenience in acquiring the information that it provides. Finally, one of the most controversial challenges that the implementation of traceability carriers may face, with the emphasis placed on the radio frequency identification (RFID) technology, is the case of ethical and privacy liberties. The use of RFID technology has profound consumer privacy, civil liberty and security implications that have been well reported in the literature ${ }^{6364}$. An additional concern related to the implementation of traceability carriers, other than the linear barcodes currently used, has to do with perceived health risks associated with these technologies. Table 2 summarises the perceived benefits and drawbacks as they were reported by food shoppers in twelve European countries that participated in the research, aimed at identifying factors that influence people's perception of such technologies ${ }^{65}$.

\section{Table 2. Benefits and drawbacks of four traceability carriers ${ }^{66}$}

[Insert Table 2 here]

In another study across four European countries, Van Rijwiik and Frewer ${ }^{67}$ investigated consumers' preferences relating to the provision of information about food traceability. The authors discovered that although there is a tendency for people to require traceability for all products, consumers believe that traceability should be mainly applied to perishable, fresh products (although conversely $25 \%$ of participants expressed the opinion that traceability was not important for fruits and vegetables). Further, the amount (concise or detailed) of traceability information, as well as the place this should appear, was investigated. Results suggested that the information required varies with product category, as summarised in Table 3.

\section{Table 3. Type of information required by consumers for different categories of food products ${ }^{68}$} [Insert Table 3 here]

Some of these consumer requirements appear contradictory (e.g. the requirement for simple information on non-perishable products whilst wishing for detailed information on canned and frozen

\footnotetext{
${ }^{63}$ Ari Juels, 'RFID Privacy' in Katherine J. Strandburg and Daniela Stan Raicu (eds), Privacy and Technologies of Identity: A Cross-Disciplinary Conversation (Springer US 2006)

${ }^{64}$ C. M. Roberts, 'Radio frequency identification (RFID)' (2006) 25 Computers \& Security 18

${ }^{65}$ supra, note 18

${ }^{66}$ supra, note 18

${ }^{67}$ supra, note 31

68 supra, note 31
} 
products that by their nature have a long shelf life). It may, however, be possible to overcome some of these contradictions by using other technologies such as QR codes (two dimensional bar codes), which enable the provision of more detailed information to interested consumers, alongside basic information on product labels or tags.

In terms of communicating traceability, Van Rijwick and Frewer's earlier work ${ }^{69}$ sounds a note of caution, arguing that the provision of the technical characteristics of traceability may confuse consumers and consequently further reduce confidence in the food supply chain. Thus the use of technology to provide detailed communication should be approached with care.

For certain foodstuffs, inherent product characteristics may also be utilised as a form of product traceability. For example, DNA tools are proposed for species identification and population assignment for fish and as a tool to authenticate the traceability of the supply chain ${ }^{70}$, whilst the use of DNA barcoding as a tool for traceability for fish and seafood, meat, dairy products and edible plants, including processed foods is also proposed ${ }^{71}$. Scientific tests such as these may be utilised by FBOs or enforcement officials to verify the authenticity of a traceability chain, subject to the availability of appropriate reference samples or databases.

Examination of labelling and packaging itself, and of supporting traceability documentation, can also be considered as an alternative means of verifying product traceability. For example, Schulze and colleagues $^{72}$ investigated the detection of altered and/ or forged documents using printing technique examination. The development of a non-destructive automated system for printed documents has also been studied ${ }^{73}$, involving methods to detect and fix the origins of the questioned printed document to link it to the source printer. Such methods could be employed by FBOs or enforcement agencies to verify product traceability through examination of packaging materials and supporting traceability documentation through the supply chain e.g. goods delivery notes.

\footnotetext{
${ }^{69}$ Wendy Van Rijswijk and Lynne J Frewer, 'Consumer perceptions of food quality and safety and their relation to traceability' [2008] British Food Journal 1034

${ }^{70}$ Rob Ogden, 'Fisheries forensics: the use of DNA tools for improving compliance, traceability and enforcement in the fishing industry' [2008] Fish \& Fisheries 462

${ }^{71}$ Andrea Galimberti and others, 'DNA barcoding as a new tool for food traceability' (2013) 50 Part 1 Food Research International 55

${ }^{72} \mathrm{C}$ Schulze and others, 'Evaluation of greylevel-features for printing technique classification in highthroughput document management systems' in S N Srihari and K Franke (eds), Computational Forensics 2nd International Workshop, IWCF 2008, Washington DC 2008 (Springer 2008)

${ }^{73} \mathrm{G}$ Gupta and others, Document Frauds: Identification and Linking Fake Document to Scanners and Printers [2007] Proceedings of the International Conference on Computing: Theory and Applications
} 
Whilst scientific and forensic methods such as these are not directly visible to the end consumer, they may provide robust data which can be communicated to the consumer on product labels or via other traceability carriers.

\section{Section Summary}

This section reviews the literature on traceability linking to consumers' perceptions and preferences for traceability labelling. It highlights the most important aspects of consumers' understanding of traceability labelling, as identified for different food products (ranging from meat and fish to fruits and vegetables, either fresh or processed) across many countries around the globe. Four drivers for traceability systems and labelling - food safety requirements, enabling technologies, country-of-origin labelling and the various value-based labelling schemes used to promote food products - are identified and a number of key consumer beliefs, perceptions and attitudes towards these traceability drivers are revealed, namely that:

- Food safety is recognised as the key driver for product traceability systems and labelling.

- Many consumers do not value traceability information unless it is associated with other product quality attributes.

- Where mandatory traceability information is carried on labels (e.g. beef in the EU) consumers fail to utilise information when making purchasing decisions.

- Consumers relate traceability to the geographic origin of products.

- Consumers' perception of traceability is influenced by the amount of information provided and the means by which it is provided.

- Consumers' requirements for traceability labelling varies across product categories and may be contradictory.

- Consumers' associate traceability with higher product costs.

\section{Traceability and consumer willingness-to-pay (behaviour)}

Section II detailed key drivers for product traceability and communication of product traceability to consumers. There is some evidence of consumers requiring traceability information particularly for fresh, perishable foods (as shown in table 3 ) and also that consumers relate traceability to desirable 
attributes of products. However, a concern was expressed about the perceived relationship between product traceability and higher product prices ${ }^{74}$.

A plethora of studies have examined consumers' preferences and willingness-to-pay (WTP) for mandatory and voluntary labelling programs associated with credence attributes related to preferences for traceability assurances. Something that appears to be important is the certification of food safety and quality, which according to a research by Loureiro and Umberger ${ }^{75}$ is the driving force for beef demand in the USA (the product was carrying a guarantee that it was USDA certified), as well as the organisation responsible for issuing traceability certificates.

For example, a number of studies have investigated the confidence the consumer places on bodies responsible for the certification of product characteristics. In a study in Georgia, examining WTP for different attributes associated with the purchase of pork ${ }^{76}$, it was reported that the public's WTP for traceability information was $48 \%$ more than that for quality certification information. In part this might be due to a lack of trust in state agency certifiers, perhaps due to the fact that such countries have been in a transitional period following the collapse of the former Soviet Union. Similarly Bai and colleagues $^{77}$ discovered that consumers in China prefer traceable milk, but they seem to have confidence on governmental and industrial certifiers, as opposed to their Georgian counterparts.

Further, the type of certification also plays an important role to consumer's preferences. Steiner and colleagues $^{78}$ evaluated the public's WTP for two labelling guarantees: one for traceability to the farm of origin and one for meat produced free of GMOs. Their findings, among others, revealed that simple traceability certifications have little value to consumers. However, people are prepared to pay premium prices to enjoy meat that has been produced without the use of genetic modification.

In the USA, Dickinson and Bailey ${ }^{79}$ found that USA consumers were willing to pay a premium in order to enjoy beef products marketed with basic traceability (which was not a mandatory requirement at that time). However, participants seemed to value certain attributes or combination of attributes more than just traceability which implies that safety guarantees are likely to be an important component of any traceability system to be developed. This premium increases further if information about the rules, procedures and practices used to produce the food product at each level of the supply

\footnotetext{
${ }^{74}$ supra, note 40

${ }^{75}$ supra, note 23

${ }^{76}$ supra, note 26

77 supra, note 20

${ }^{78}$ supra, note 25

${ }^{79}$ supra, note 21
} 
chain (including animal treatment) is revealed to the public. This is evident more regarding beef than pork meat. When all three attributes were present in a single product, participants revealed a significantly more willingness to pay for it. Interestingly, the average bid for a product that has all three characteristics was less than the sum of the bids for individual characteristics. This finding may suggest that people's WTP decreases as additional attributes are added. Dickinson and Bailey extended their research to the UK and revealed that UK consumers do not value the characteristic of meat safety any higher than traceability alone. Further, they were willing to pay a considerable premium for assurances on humane animal treatment. An important finding was that demographic variables were not significant determinants of people's WTP. This reveals that the market for traceable meat products is broad and cannot be determined by socio-demographic characteristics ${ }^{80}$. In another European study, French and German consumers expressed their preference for place of origin indication as the most important attribute of the product ${ }^{81}$. Recent reports on the extension of mandatory $\mathrm{COOL}$ in the EU to other food types support this work, showing that the preference for $\mathrm{COOL}$ varies in different member states ${ }^{82}$, and that whilst consumers express an interest in COOL they are not generally willing to pay an increased price for this information ${ }^{83}$.

Gracia and Zeballos ${ }^{84}$ discovered three main underlying attitudes towards the EU system with respect to the mandatory traceability and labelling system in the beef supply chain: 1) traceability is an obligation and legal requirement that will only induce higher production costs and therefore higher beef prices, 2) traceability will provide benefits because it will induce higher safety perceptions and confidence in beef safety and 3) traceability does not imply higher meat quality and does not provide higher confidence in beef safety. Verbeke and colleagues ${ }^{85}$ examined the attitudes of Belgian meat consumers about pork, and argue traceability systems would work best when coupled with efforts to improve intrinsic qualities such as leanness, taste, tenderness, and the extrinsic quality of healthiness. Interestingly, Hobbs ${ }^{86}$ indicated traceability is the most important characteristic desired by large UK beef processors when purchasing cattle from farmers and also found that the ease of traceability ranked ahead of prices paid to processors as an important characteristic to consider when

\footnotetext{
${ }^{80}$ supra, note 22

81 supra, note 24

82 supra, note 58

83 supra, note 57

${ }^{84}$ Azucena Gracia and Gabriela Zeballos, 'Attitudes of Retailers and Consumers toward the EU Traceability and Labeling System for Beef' (2005) 36 Issue 3 Journal of Food Distribution Research 45

${ }^{85}$ Wim Verbeke and others, 'Consumer perception, facts and possibilities to improve acceptability of health and sensory characteristics of pork' (1999) 53 Meat Science 77

$86 \mathrm{Jill}$ E Hobbs, 'A transaction cost analysis of quality, traceability and animal welfare issues in UK beef retailing'[1996] British Food Journal 16
} 
supermarkets in the UK purchased meat. ${ }^{87}$ The last arguments underline that traceability is a characteristic requested among all participants in the supply chain, however, consumers are less interested in it per se, unless it is accompanied by other quality characteristics ${ }^{88}$.

To summarise, this investigation of consumer preferences and WTP for traceability information has revealed interesting findings. Taking into account the diverse cultural, religious, societal and economic components of individual decision making, as well as the different types of food products, the conclusions (focusing on fresh and perishable products) that can be drawn are as follows:

- Consumers require traceability information particularly for fresh, perishable foods

- Consumers relate traceability to desirable product attributes.

- Consumers' trust of certification agencies differ from country to country.

- Although traceability is requested by consumers, they are not interested in it per se unless it is coupled with other quality characteristics.

- Demographic variables are not significant in determining people's WTP for traceability.

- Consumers believe that mandatory traceability implementation can deliver higher product safety, but not necessarily higher product quality, and believe that traceability will have a negative impact on prices.

\section{Discussion and Conclusion}

At first glance, traceability in the food supply chain appears straightforward for all stakeholders, with clear benefits in terms of product safety and assurance, for food chain actors and consumers alike. With closer examination, complexities appear: regulatory requirements, technological challenges, consumer understanding and costs all have to be taken into consideration.

This paper has explored the reasons, from the consumer point of view, that can drive forward the application and communication of traceability. It discussed issues pertaining to food safety, value labels, country-of-origin and the use of technology, and has presented some of the perceptions and preferences that consumers hold. Indeed, the implementation of traceability systems and labelling of

\footnotetext{
87 Jill E. Hobbs, 'Transaction costs and slaughter cattle procurement: Processors' selection of supply channels' [1996] Agribusiness 509

${ }^{88}$ supra, note 35
} 
traceability information for food products faces difficulties that may be partly attributed to people's perceptions about the benefits and drawbacks of traceability and the way these have been communicated to them by the industry, regulators and others. Implications for practice by FBOs and enforcers, and recommendations for future research can be determined.

One area which appears to have been little researched, is the relationship between food traceability, the prevention of food fraud and consumers' perception of this. Whilst it is not possible to determine the exact amount of fraudulent activity in the food supply chain, there are growing concerns amongst industry, enforcement officials and consumers about a global escalation and spread of fraudulent activities along the food supply chain. The central role that enhanced traceability plays in modern industry assurance systems ${ }^{89}$ and guidance to protect $\mathrm{FBOs}$ from food fraud and other deliberate attacks, ${ }^{90} 91$ demonstrates the impact that food fraud awareness is having as a driver of enhanced risk assessment within FBOs. A key question remaining for the food industry is whether concerns about food fraud will become a credible driving force for more than risk assessment, i.e. both enhanced systems implementation and communication of additional traceability information to consumers.

Where the communication of traceability to the consumer relies on simple labelling alone, this leaves open the possibility of product mislabelling and counterfeiting. Certain product sectors might therefore particularly benefit from the utilisation of technologies as part of traceability systems to deter fraudulent activities, for example the fish and seafood industry ${ }^{92}$. The use of DNA-testing for species identification, for example, can act as both an enforcement tool and a deterrent against the mislabelling of fish species, typically where a high value fish species is substituted with a lower value one.

This research provides other thought provoking insights, for example, the link which consumers make between $\mathrm{COOL}$ and traceability. $\mathrm{COOL}$ seems to be important for consumers as they demand more information on the origin of foods. It could also prove useful to producers and processors, who would like to market their products and gain premium prices by taking advantage of certification schemes. However as consumers can not verify geographic origin themselves by looking at or eating the food, it remains an area which is highly susceptible to fraudulent activity, as demonstrated by the well-

\footnotetext{
${ }^{89}$ supra, note 15

${ }^{90}$ supra, note 14

91 supra, note 13

92 Miguel Costa Leal and others, 'Seafood traceability: current needs, available tools, and biotechnological challenges for origin certification' (2015) 33 Issue 6 Trends in Biotechnology 331
} 
reported mislabelling of "Italian" olive oils ${ }^{93}$ and by recent reports of supposedly fraudulent labelling of "Scottish" beef ${ }^{94}$. A requirement to include further traceability information on labels might deter those committing fraud but equally, might present an opportunity for fraudulent misrepresentation.

Even in a relatively sophisticated regulatory environment such as the EU, current mandatory traceability requirements ("one step forwards, one step back") are recognised as inadequate to support robust traceability for the geographic origin of products ${ }^{95}$. Hence the application of more stringent traceability requirements by $\mathrm{FBOs}$, the enforcement of such and perhaps the use of new technologies to enable consumers to play an active role in verification of claims, may be required to mitigate the risk of food fraud related to COOL.

All such activities have financial implications for FBOs and enforcement agencies, and it is unclear at present whether consumers would be willing to pay for enhanced traceability coupled with geographic origin labelling. For example, consumers may come to perceive quantity rather than quality of information as an indicator of authenticity. It is likely that the additional costs incurred by businesses would be seen as not being cost effective, and in particular, it may not be perceived value adding by consumers, unless there are other key quality attributes in the information provided on labels that enhance or reinforce consumer knowledge about the product.

Further research is required to explore consumers' needs and willingness-to-pay for traceability, demand for product differentiation and the associated costs for traceability devices, including smart labelling and packaging which would enhance investment in traceability in the food supply chain. Additionally, there is a need to establish whether the prevention of food fraud can act as an independent factor on consumers' willingness-to-pay for products or whether this would be subsumed into traceability as a whole. Finally, there is a need to investigate the communication of the pros and cons of new technologies and systems to consumers, as there may be risks for FBOs in embracing new traceability technologies if their use is miscommunicated to consumers.

\footnotetext{
${ }^{93}$ Richard Evershed and Nicola Temple, 'A Slippery Deal' in Sorting The Beef From The Bull (Bloomsbury Publishing Plc 2016)

${ }^{94}$ Mary Nicolson, 'Exclusive: Meat plants probe over Scottish beef' The Courier (Dundee, $12^{\text {th }}$ November, 2016) <https://www.thecourier.co.uk/fp/news/scotland/312704/exclusive-meat-plants-probe-scottish-beef/ > accessed $29^{\text {th }}$ November 2016

${ }^{95}$ supra, note 57
} 